\title{
When Small Issues Can Cause Big Problems: A Review of the Evidence- Based Prevention and Treatment of Gallstones Following Bariatric Surgery
}

Luca Leuratti

Department of Emergency-Urgency, University of Bologna, Italy

\section{Summary}

Background: The dramatic weight loss achieved with medical or surgical therapies is associated with an increased incidence of biliary pathologies, due to high incidence of gallstones formation. In the last 35 years, this issue has been addressed differently, along with the development of mini-invasive techniques applied to bariatric patients suitable for reducing the overall surgical risk. Indeed, since a two staged approach was introduced in the current practice to treat obesity, a consensual decrease in prophylactic cholecystectomies in course of the primary bariatric procedure was reported

Methods: A systematic review of the literature was performed using the most common electronic sources. A manual search of the references was also performed. The most significant results obtained were related with the different mechanisms involved in the bariatric surgeries to point out possible predictive factors for the development of gallstones; modified strategies to treat possible complication are exposed.

Results: No consensus is available on how to prevent and manage asymptomatic gallstones. Specific circumstances are discussed to point out the differences with the general population. A brief summary about the possible causes, working diagnoses, and timing for treatment is also suggested upon last evidences.

Conclusion: since the laparoscopy changed the old paradigm of maximizing all the possible procedures in the same laparotomy, times seem mature for a consensus on the timing to tackle biliary problems, because the widespread of bariatric surgery and the long life expectance of the ex-obese patients will increase the incidence of post-surgical gallstones.

\section{Background}

The relationship between morbid obesity and gallstones was first defined in 1975 [1-2]. Since the first experiences, the authors reported an increased risk for this condition and its related complications, if compared with the general population. Further studies investigated the possible causes, and reported an impaired contraction of the gallbladder, which was dilated in most cases [3], and a different composition of bile in the gallbladder (much richer in cholesterol [48] and pro-nucleating factors such as mucin [5,7,9-10]) in the obese population. Moreover, an increased risk for new onset gallstones was observed after a dramatic weight loss achieved both with surgical or medical therapies [11-12].

During the years 1980s and 1990s the main trend was to reduce the number of procedures in obese patients since most of the operations at that time were performed with an open approach, and a second laparotomy (in the early days of laparoscopy a second look after a laparotomy was considered almost a contraindication) to treat symptomatic gallstones exposed the patient to an excessive risk of complications. This resulted in an increased number of prophylactic cholecystectomies performed during the primary bariatric procedure, regardless of the presence of gallstones (Figure 1). The first procedure codified with a routine gallbladder removal was the biliopancreatic diversion in 1980 [13]. Hence, the preventive removal of the gallbladder was advocated, since it was "deprived of its functional significance", using Scopinaro's words, and because of an increased incidence of postoperative symptomatic biliary disease (experienced by the $25 \%$ of the patients within the first postoperative year if the gallbladder was left in place, according with the original experience in 1979 [14]). The need for preventive measure to avoid further symptoms requiring a removal of gallbladder, suggested a low threshold for offering the patients a prophylactic cholecystectomy [15].

\section{Publication History:}

Received: May 05, 2014

Accepted: June 19, 2014

Published: June 21, 2014

Keywords:

Bariatric Surgery, Gallstones,

Gallbladder

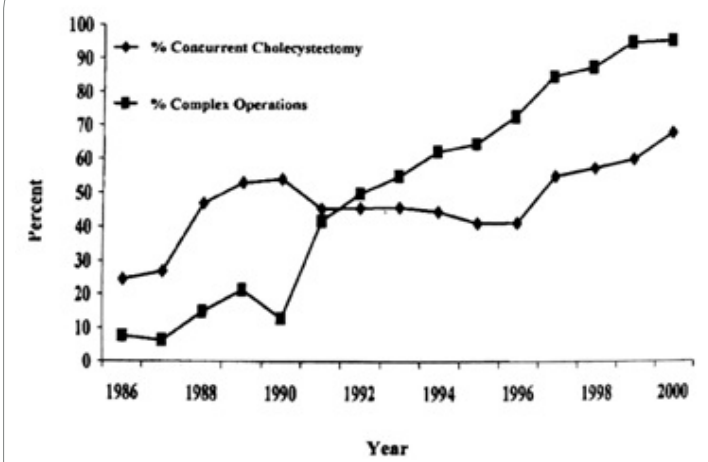

Figure 1: Initial trend for prophylactic cholecystectomies during bariatric surgeries according with EE Mason.

With the establishing of new standard of care, in particular the diffusion of laparoscopy, surgical strategies have changed accordingly, since it was possible to fractionate the overall risk of a surgical procedure,

"Corresponding Author: Dr. Luca Leuratti, Department of Emergency-Urgency, University of Bologna, Italy; E-mail: luca.leuratti@gmail.com

Citation: Leuratti L (2014) When Small Issues Can Cause Big Problems: A Review of the Evidence-Based Prevention and Treatment of Gallstones Following Bariatric Surger. Int J Gastroenterol Disord Ther 1: 101. doi: http:// dx.doi.org/10.15344/2393-8498/2014/101

Copyright: ( $) 2014$ Leuratti. This is an open-access article distributed under the terms of the Creative Commons Attribution License, which permits unrestricted use, distribution, and reproduction in any medium, provided the original author and source are credited. 
Citation: Leuratti L (2014) When Small Issues Can Cause Big Problems: A Review of the Evidence-Based Prevention and Treatment of Gallstones Following Bariatric Surger. Int J Gastroenterol Disord Ther 1: 101. DOI: http://dx.doi.org/10.15344/2393-8498/2014/101

Page 2 of 5

without the great drawback represented by the formation of adhesions. Moreover, the patients were more likely to accept a second laparoscopy rather than a second laparotomy. If a dramatic increase in number of cholecystectomies was reported in the years 1987 to 2002 [16], since then a reverse of the trend was reported, with a super-selective approach proposed for gallbladder removal and the bariatric procedure at once. Despite the generalized consensus for the current management of the biliary prophylaxis, there is no consensus on how to prevent the gallstones formation, and there is still a lack of discussion on whether it could be worthy to propose a medical prophylaxis. Moreover, if on one hand the bariatric surgeons are more used to the post-surgical anatomy and the possible limitations related to the specific technique, most of the physicians and general surgeons involved in the management of gallstones or of its complications should share similar knowledges in order to find the best strategy as possible. In fact, with the increasing number of patients who will require bariatric surgery, establishing a closer collaboration between physicians and bariatric surgeons could be important.

Aim of this brief presentation is to review and summarize the main evidences in term of biliary stones incidence and management when a patient had (or is planning to have) a bariatric procedure, with particular regard to the impact of the mechanism of the different surgeries on the natural history of the condition.

Bariatric Procedures (Figure 2)

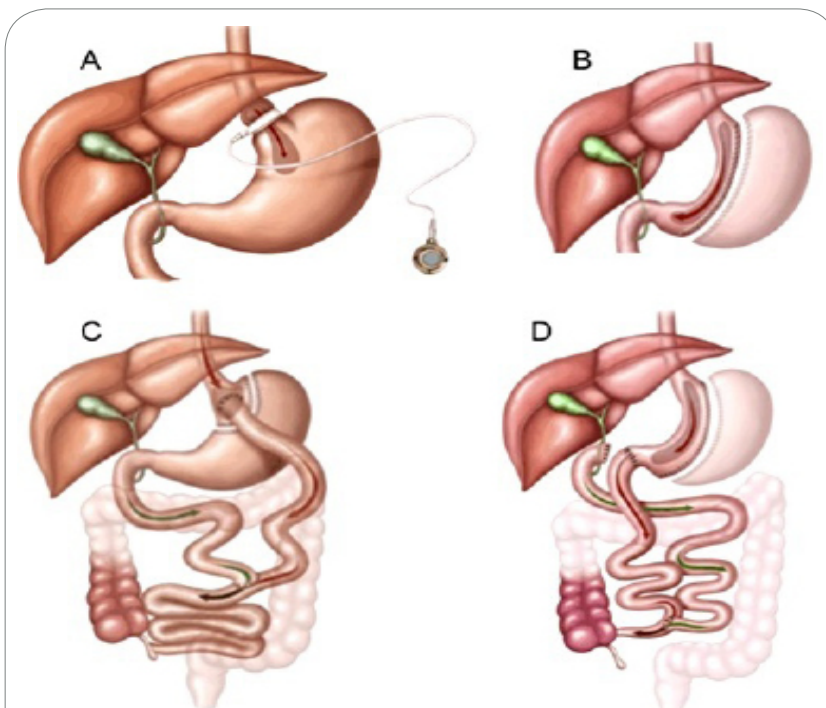

Figure 2: Sketch representing the most commonly performed procedures: A: adjustable gastric band; B: sleeve gastrectomy; C: Roux-en-Y gastric bypass; D duodenal switch.

Adjustible gastric band: it is a pure restrictive procedure, in course of which the stomach is surrounded with a silicone band immediately below the cardia to create a proximal small pouch, joined to the bigger stomach through a communication with variable calibre, which can be adjusted by injecting fluid into a subcutaneous port. The expected excess of weight loss (EWL) is $45-55 \%$ in the long term. In comparison with other bariatric procedures there are no metabolic mechanisms appreciable in the peri-operative days. The alimentary transit passes through the duodenum as in the general population, so that the main lithogenic effect is exerted by the change in the meal composition (mainly constituted of protein instead of fat), and reduction of overall volume of the chyme. These factors contribute to the risk of gallstones together with the increased secretion of cholesterol into the bile, related with the weight loss. A transient dehydration consequent to a period of adaptation to the gastric restriction could also contribute to the increased density of the bile in the gallbladder and to the increased risk of precipitating of cholesterol crystals.

Vertical banded gastroplasty: this is actually considered an obsolete procedure performed mainly before the advent of laparoscopy and of linear cutting-stapler. It is a pure restrictive procedure with slightly better results in term of weight loss (EWL 55-60\%), and same impact in term of gallstones formation. It is worthy to mention it, since the gastro-gastric outlet was calibrated on a size of 34-36 $\operatorname{Fr}(\sim 1,1 \mathrm{~cm})$, and it could represent a limit for passing through the outlet of a sideview enteroscope. Moreover, while the incidence of gallstones after adjustable gastric band was reported as being very low $(2,6 \%$ in a randomized series of 2008 [17], and $0 \%$ in a similar experience in 2014 [18]), the incidence of gallstone formation after vertical banded gastroplasty was reported to be much higher (up to 7\%) [19].

Roux-En-Y gastric bypass: It combines the restriction of the stomach volume by creating a small $(25-30 \mathrm{cc})$ gastric pouch immediately below the cardia, with the bypass of the foregut (duodenum and 40-70 $\mathrm{cm}$ of jejunum). It provides good results in term of weight loss (EWL $65-75 \%$ ), and good QOL with a relatively small risk of side effects. The incidence of gallstones following such a procedure varies from 6,7 to $52,8 \%$ [20-28], becoming symptomatic in a percentage ranging from $3 \%$ to $8 \%$ when no prophylaxis with UDCA is established [29-32]. Following the early experiences with prophylactic cholecistectomies performed routinely at the moment of the primary bariatric procedure (with or without evidence of specific pathology) the incidence of pathologic specimens was between $75 \%$ and $82 \%$ [33-36]. There are several mechanisms impaired in the gastric bypass that can be responsible for gallstone formation:

1. The reduction of the gastric capacity is associated with a complete diversion of the duodenum. Traditionally, this is associated with an impaired contraction of the gallbladder with consequent gallstones formation. Following recent evidences, CCK was found to be increased after gastric bypass, and strongly associated with the appetite suppression experienced by the patients [34]. The same evidences were supported by several studies on animal models [35-36]. Therefore we need to look for different mechanisms.

2. While creating the pouch, the surgeon could opt for an approach through the pars flaccida (which always implies the division of the Vagus nerve), as alternative to the perigastric approach (which exposes to a higher risk of bleeding). It is still unclear whether the division of the vagus nerve could be responsible for an extra risk of biliary stones in relation to a decreased motility of the gallbladder. None of the available studies has considered this detail in reporting the surgical technique used in the study. Indeed this could be responsible for the gap reported in term of gallstone incidence following Roux-en-Y gastric bypass, when compared with the sleeve gastrectomy.

3. The gastric bypass (as other bariatric procedures) leads to an unconstant weight loss which is greatest within the first 3-6 months postoperatively. This dramatic weight loss is responsible for the peripheral fat mobilization and its increased excretion into the biliary ducts, thus supersaturating the bile. 
Citation: Leuratti L (2014) When Small Issues Can Cause Big Problems: A Review of the Evidence-Based Prevention and Treatment of Gallstones Following Bariatric Surger. Int J Gastroenterol Disord Ther 1: 101. DOI: http://dx.doi.org/10.15344/2393-8498/2014/101

4. Bariatric surgery, and the gastric bypass in particular, is associated with a reduction in fluid intake, thus increasing the risk of precipitating crystals both in the biliary and renal districts [40].

Sleeve gastrectomy: It was supposed to be the first stage of a two staged bilio-pancreatic diversion, allowing the super-obese patient to lose enough weight to reduce the risk for the second (more invasive) surgery. Since it provides excellent results as an independent procedure (EWL 60-65\%), its application found an enthusiastic diffusion worldwide. Despite the apparent mechanism seems to be related with a pure restriction of the stomach volume, several series showed an articulate, and still unknown, metabolic mechanism responsible for the blood sugar control before a significant weight loss occurs, and for the complete lack of appetite (due to suppression in the secretion of ghrelin). Recent studies on the gastric emptying after sleeve gastrectomy have witnessed a rapid passage through the foregut, thus permitting to speculate it could be considered functionally as a gastric bypass [41-43]. Despite the accelerated transit through the small bowel, the duodenal passage is preserved, as well as the Vagus nerve. Possibly this is the cause for a slightly, but significant, lower incidence of gallstones post-surgery as reported in several series $[17,44]$.

Billio-pancreatic diversion or duodenal switch: it is the most effective procedure in term of weight loss, providing an average EWL of $75-85 \%$. These results are due to the selective malabsorption for fats contained in the meal, since the length of the common channel is tailored upon the overall length of the small bowel in measure of $10 \%$ of the total. Among the several possible side effects such as deficiencies of liposoluble vitamin and calcium or protein malnutrition, the steatorrhoea frequently associated with this procedure leads to an overall loss of micelles containing also biliary acids with consequent impairment of the enterohepatic circuit. The reduction in the overall concentration of the biliary acids would eventually increase the risk determined by the supersaturation of the bile. Indeed most of the surgeons who propose such kind of malabsorptive procedures perform a cholecystectomy at the same time. Despite the early experience with biliopancreatic diversion suggested a cholecystectomy would have prevented a high incidence of postoperative symptomatic gallstones, Bardaro et al. in 2007 presented a series of 219 patients, where only $8,7 \%$ of them required a cholecystectomy after the surgery. Since 38 of them had a cholecystectomy already performed at the beginning of the follow-up, the adjusted ratio upon who still had the gallbladder after bariatric surgery was $10,5 \%$, a similar value if compared with most of the bypass experiences [45].
Despite the several possible mechanisms advocated, the loss of weight has been identified as the only predictive factor to develop gallstones. In a recent retrospective experience comparing gastric bypass, gastric band and sleeve gastrectomy, the only predictive element was found to be an EWL greater than $25 \%(B=1,482$ odds ratio 4.44 , CI 1,549 $12,498 \mathrm{p}<0.005)$ [17].

\section{Medical Strategies and Special Situations}

The trend towards a reduction in the number of prophylactic cholecystectomies performed at the same time of bariatric surgery $[9,19,26,46-48]$, and the diffusion of bariatric surgery itself determines an overlap of possible causes in the working diagnosis of an epigastric pain. In fact this could have different causes according with the past bariatric history:

-Gastric band: slippage, erosion, infection

-Gastric bypass: marginal ulcer, internal hernia

-Sleeve gastrectomy: peptic ulcer in the sleeve, dislocation in the chest

-Bilio-pancreatic diversion and duodenal switch: the same of sleeve gastrectomy and small bowel volvulus

Usually it is easy to rule out the presence of concomitant causes for symptoms with routine investigations and physical examination. A special mention should be addressed to exceptional cases that would require an unusual management. For example, traditional endoscopic approaches to the biliary ampulla would be impossible after the bypass of the foregut. In such patients several authors presented new solutions, the most diffuse and well established being the laparoscopic assisted ERCP [49-52] and the double-balloon enteroscopy ERCP [53-56]. Only recently a fortunate radiological management of CBD stones developed following gastric bypass and subsequent laparoscopic cholecystectomy was presented. In this experience the sphyncterotomy was successfully performed in course of percutaneous transhepatic cholangiography [57].

While the surgically assisted ERCPs implies the risk of a general anesthesia, and the risk of a gastrotomy used to access the foregut in an anterograde fashion, the retrograde ERCP performed with the help of the double balloon technique is generally perceived as safer and less invasive, despite most of authors suggest to perform it under deep sedation or general anesthesia. Both approaches have the drawback of long time required to complete the procedure (up to 90 minutes). Following our experience with a less invasive approach through interventional radiology, we proposed an algorithm for the management of the gastric bypass patient who experiences CBD stones [58] (Figure 3). Similar algorithms should be proposed also for

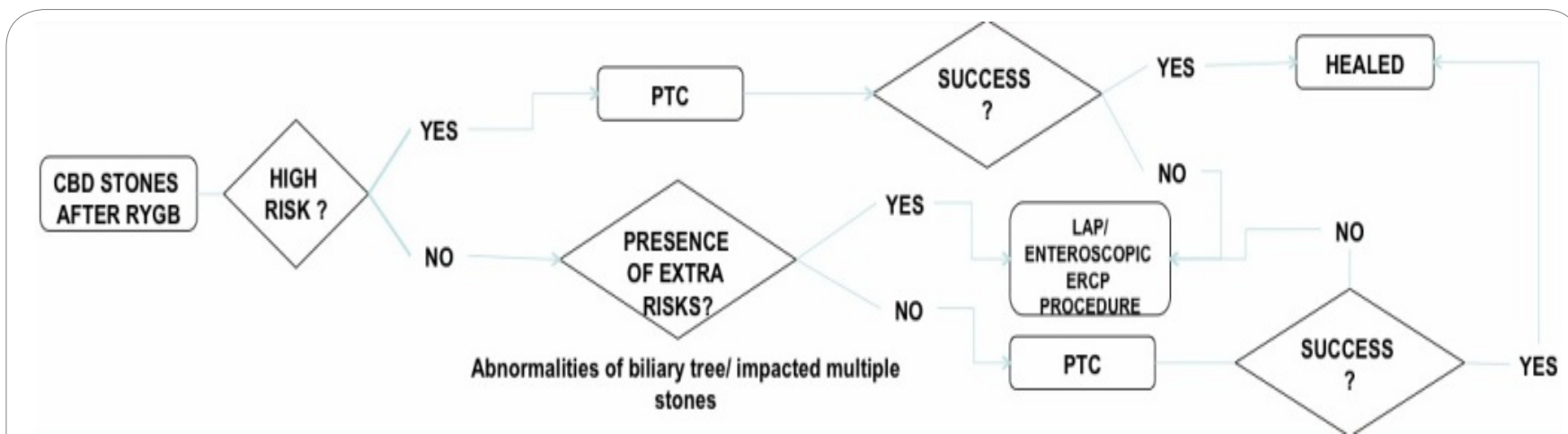

Figure 3: Algorithm proposed to manage CBD stones after gastric bypass surgery. 
Citation: Leuratti L (2014) When Small Issues Can Cause Big Problems: A Review of the Evidence-Based Prevention and Treatment of Gallstones Following Bariatric Surger. Int J Gastroenterol Disord Ther 1: 101. DOI: http://dx.doi.org/10.15344/2393-8498/2014/101

the other bariatric procedures, even if less invasive, like the adjustable gastric band, where the exceptionality is related to the presence of foreign material, which could be contaminated by the infected bile, especially if it is expected a combined approach involving surgery.

A similar awareness is suggested also when considering the prevention of gallstones. If most series report an overall incidence of cholecystectomies after a surgically induced weight loss similar to the general population [9,46-48] (regardless to the increased incidence of complications suggests to establish at least a medical prevention using bile acids analogues. Indeed these drugs demonstrated good results in reducing the incidence of gallstones following a significant weight loss in previous series and meta-analysis $[12,26,29,32]$. The main concerns for a wide diffusion of such drugs are represented by costs and lack of compliance to the therapy, but there are no arguments against their use, despite a lack of data about side effects in the obese population. When a medical prevention is established, adjustment of dose upon the previous surgical technique is advised, since a malabsorptive procedure would require a higher dose than usual due to the more pronounced depletion of the biliary acids in these patients.

Another controversial argument is whether the bypass procedures could be responsible for changes in the excluded stomach potentially in relation with a bile reflux. Since 1985, authors tried to reach the excluded stomach to verify the mucosal changes after a prolonged period of diversion of the alimentary transit. In particular, Flickinger was the first who reported the presence of bile in the gastric antrum in all the patients with a variable degree of gastritis of the stomach remnant after the gastric bypass [58]. It is anyway questionable whether this evidence could be explained by the fact that the endoscopy was performed in a retrograde fashion, thus creating a flow of air which cloud have been responsible for the presence of the bile in the stomach remnant. In a recent experience with antegrade endoscopy performed in patients who had a functionally excluded gastric bypass[60], a significant degree of gastritis was detected in the antrum of most patients, while the presence of bile was not significantly associated with the degree of gastritis. Surely the moment there are no evidences to support the presence of a biliary reflux after gastric bypass procedures with a potential to develop clinical significant lesions.

\section{Conclusion}

The actual trend towards a more conservative approach in the prevention of gallstones formation after bariatric surgery means that more and more physicians will be required to face the biliary complications that could occur. Despite and increased risk is not expected, the modified upper GI anatomy could represent a challenge for the gastroenterologist, in term of accessibility to the duodenum and reduced entero-hepatic circuit. A multidisciplinary approach involving bariatric surgeons and gastroenterologists could point out solutions where the general guidelines cannot be applied.

\section{References}

1. Freeman JB, Meyer PD, Printen KJ, Mason EE, DenBesten L (1975) Analysis of Gallbladder Bile in Morbid Obesity. Am J Surg 129: 163-166.

2. Mabee TM, Meyer P, DenBesten L, Mason EE (1976) The Mechanism of Increased Gallstone Formation in Obese Human Subjects. Surgery 79: 460-468.

3. Marzio L, Capone F, Neri M, Mezzetti A, De Angelis C, et al. (1988) Gallbladder Kinetics in Obese Patients. Effect of a Regular Meal and a Low Calorie Meal. Dig Dis Sci 33:4-9.
4. Bennion LJ, Grundy SM (1975) Effects of obesity and caloric intake on biliary lipid metabolism in man. J Clin Invest 56: 996-1011.

5. Broomfield PH, Chopra R, Sheinbaum RC, Bonorris GG, Silverman A, et al. (1988) Effects of ursodeoxycholic acid and aspirin on the formation of lithogenic bile and gallstones during loss of weight. $\mathrm{N}$ Engl $\mathrm{J}$ Med 319: $1567-1572$

6. Mazzella G1, Bazzoli F, Festi D, Ronchi M, Aldini R, Roda A, et al. (1991) Comparative evaluation of chenodeoxycholic and ursodeoxycholic acids in obese patients. Effects on biliary lipid metabolism during weight maintenance and weight reduction. Gastroenterology 101: 490-496.

7. Marks JW, Bonorris GG, Albers G, Schoenfield LJ (1992) The sequence of biliary events preceding the formation of gallstones in humans. Gastroenterology 103: 566-570.

8. Gebhard RL, Prigge WF, Ansel HJ, Schlasner L, Ketover SR, et al. (1996) The role of gallbladder emptying in gallstone formation during diet-induced rapid weight loss. Hepatology 24: 544-548.

9. Shiffman ML, Sugerman HJ, Kellum JM, Moore EW (1992) Changes in gallbladder bile composition following gallstone formation and weight reduction. Gastroenterology 103: 214-221.

10. Shiffman ML, Shamburek RD, Schwartz CC, Sugerman HJ, Kellum JM, et al. (1993) Gallbladder mucin, arachidonic acid, and bile lipids in patients who develop gallstones during weight reduction. Gastroenterology 105: 1200-1208.

11. Gustafsson U, Benthin L, Granström L, Groen AK, Sahlin S, et al. (2005) Changes in gallbladder bile composition and crystal detection time in morbidly obese subjects after bariatric surgery. Hepatology 41: 1322-1328.

12. Stokes CS, Gluud LL, Casper M, Lammert F (2014) Ursodeoxycholic Acid and Diets Higher in Fat Prevent Gallbladder Stones During Weight Loss: A Meta-analysis of Randomized Controlled Trials. Clin Gastroenterol Hepatol 12: $1090-1100$

13. Scopinaro N, Gianetta E, Civalleri D, Bonalumi U, Bachi V (1980) Two years of clinical experience with biliopancreatic bypass for obesity. Am J Clin Nutr 33: 506-514.

14. Scopinaro N, Gianetta E, Civalleri D, Bonalumi U, Bachi V (1979) Biliopancreatic bypass for obesity: II. Initial experience in man. Br J Surg 66: 618-620.

15. Deitel M, Petrov I (1987) Incidence of symptomatic gallstones after bariatric operations. Surg. Gynecol Obstet 164: 549-552.

16. Mason EE, Renquist KE (2002) Gallbladder Management in Obesity Surgery. Surg Gynecol Obstet 12: 222-229.

17. Li VK, Pulido N, Fajnwaks P, Szomstein S, Rosenthal R, et al. (2009) Predictors of Gallstones formation after bariatric surgery: a multivariate analysis of risk factors comparing gastric bypass, gastric banding, and sleeve gastrectomy. Surg Endosc 23: 1640-1644

18. Moon RC, Teixeira AF, DuCoin C, Varnadore S, Jawad MA (2014) Comparison of cholecystectomy cases after Roux-en-Y gastric bypass, sleeve gastrectomy, and gastric banding. Surg Obes Relat Dis 10: 64-70.

19. Deitel M, Smith L, Harmantas A (1994) Laparoscopic Cholecystectomy after Vertical Banded Gastroplasty. Obes Surg 4: 13-15

20. Griffen WO Jr, Young VL, Stevenson CC (1977) A prospective comparison of gastric and jejunoileal bypass procedures for morbid obesity. Ann Surg 186: 500-509.

21. Wattchow DA, Hall JC, Whiting MJ, Bradley B, lannos J, et al. (1983) Prevalence and treatment of gall stones after gastric bypass surgery for morbid obesity. Br Med J 286:763.

22. Amaral JF, Thompson WR (1985) Gallbladder disease in the morbidly obese. Am J Surg 149: 551-557.

23. Sugerman HJ, Brewer WH, Shiffman ML, Brolin RE, Fobi MA, et al. (1995) A multicenter, placebo-controlled, randomized, double-blind, prospective trial of prophylactic ursodiol for the prevention of gallstone formation following gastric-bypass-induced rapid weight loss. Am J Surg 169: 91-96. 
Citation: Leuratti L (2014) When Small Issues Can Cause Big Problems: A Review of the Evidence-Based Prevention and Treatment of Gallstones Following Bariatric Surger. Int J Gastroenterol Disord Ther 1: 101. DOI: http://dx.doi.org/10.15344/2393-8498/2014/101

24. Scott DJ, Villegas L, Sims TL, Hamilton EC, Provost DA, et al. (2003) Intraoperative ultrasound and prophylactic ursodiol for gallstone prevention following laparoscopic gastric bypass. Surg Endosc 17: 1796-1802.

25. Iglézias Brandão de Oliveira C, Adami Chaim E, da Silva BB (2003) Impact of rapid weight reduction on risk of cholelithiasis after bariatric surgery Obes Surg 13: 625-628.

26. Villegas L, Schneider B, Provost D, Chang C, Scott D, et al. (2004) Is routine cholecystectomy required during laparoscopic gastric bypass? Obes Surg 14: 206-211.

27. Teivelis MP, Faintuch J, Ishida R, Sakai P, Bresser A, et al. (2007) Endoscopic and Ultrasonographic Evaluation Before and After Gastric Bypass for Morbid Obesity. Arq Gastroenterol 44: 8-13.

28. Bastouly M, Arasaki CH, Ferreira JB, Zanoto A, Borges FG, et al. (2009) Early Changes in Postprandial Gallbladder Emptying in Morbidly Obese Patients Undergoing Roux-en-Y Gastrc Bypass: correlation with the occurrence of biliary sludge and gallstones. Obes Surg 19: 22-28

29. Hamad GG, Ikramuddin S, Gourash WF, Schauer PR (2003) Elective cholecystectomy during laparoscopic Roux-en-Y gastric bypass: is it worth the wait? Obes Surg 13: 76-81.

30. Caruana JA, McCabe MN, Smith AD, Camara DS, Mercer MA, et al. ( 2005) Incidence of symptomatic gallstones after gastric bypass: is prophylactic treatment really necessary? Surg Obes Relat Dis 1: 564-567; discussion 567-568.

31. Escalona A1, Boza C, Muñoz R, Pérez G, Rayo S, et al. (2008) Routine preoperative ultrasonography and selective cholecystectomy in laparoscopic Roux-en-Y gastric bypass. Why not? Obes Surg $18: 47-51$.

32. Taylor J, Leitman IM, Horowitz M (2006) Is routine cholecystectomy necessary at the time of Roux-en-Y gastric bypass? Obes Surg 16: 759761.

33. Fobi M, Lee H, Igwe D, Felahy B, James E, et al. (2002) Prophylactic cholecystectomy with gastric bypass operation: incidence of gallbladder disease. Obes Surg 12: 350-353.

34. Guadalajara H, Sanz Baro R, Pascual I, Blesa I, Rotundo GS, et al. (2006) Is prophylactic cholecystectomy useful in obese patients undergoing gastric bypass? Obes Surg 16: 883-885.

35. Nougou A, Suter M (2008) Almost routine prophylactic cholecystectomy during laparoscopic gastric bypass is safe. Obes Surg 18: 535-539.

36. Liem RK, Niloff PH (2004) Prophylactic cholecystectomy with open gastric bypass operation. Obes Surg 14: 763-765.

37. Jacobsen SH1, Olesen SC, Dirksen C, Jørgensen NB, Bojsen-Møller KN et al. (2012) Changes in Gastrointestinal Hormone Responses, Insulin Sensitivity and Beta cell Function within 2 weeks after Gastric Bypass in non Diabetic Subjects. Obes Surg 22: 1084-1096.

38. Mumphrey MB, Patterson LM, Zheng H, Berthoud HR (2013) Roux-en-Y gastric bypass surgery increases number but not density of CCK-, GLP$1-, 5-\mathrm{HT}-$, and neurotensin-expressing enteroendocrine cells in rats. Neurogastroenterol Motil 25: e70-e79.

39. Steinert RE, Feinle-Bisset C, Geary N, Beglinger C (2013) Digestive physiology of the pig symposium: secretion of gastrointestinal hormones and eating control. J Anim Sci 91: 1963-1973.

40. Agrawal V, Liu XJ, Campfield T, Romanelli J, Enrique Silva J, et al. (2014) Calcium oxalate supersaturation increases early after Roux-en-Y gastric bypass. Surg Obes Relat Dis 10: 88-94.

41. Baumann T, Kuesters S, Grueneberger J, Marjanovic G, Zimmermann L, et al. (2011) Time-resolved MRI after ingestion of liquids reveals motility changes after laparoscopic sleeve gastrectomy-preliminary results. Obes Surg 2: 95-101.

42. Braghetto I, Davanzo C, Korn O, Csendes A, Valladares H, et al. (2009) Scintigraphic evaluation of gastric emptying in obese patients submitted to sleeve gastrectomy compared to normal subjects. Obes Surg 19: 15151521.
43. Shah S, Shah P, Todkar J, Gagner M, Sonar S, et al. (2010) Prospective controlled study of effect of laparoscopic sleeve gastrectomy on small bowel transit time and gastric emptying half-time in morbidly obese patients with type 2 diabetes mellitus. Surg Obes Relat Dis 6: 152-157.

44. Li VK, Pulido N, Martinez-Suartez P, Fajnwaks P, Jin HY, et al. (2009) Symptomatic gallstones after sleeve gastrectomy. Surg Endosc 23: 24882492.

45. Bardaro SJ, Gagner M, Consten E, Inabnet WB, Herron D, et al. (2007) Routine cholecystectomy during laparoscopic biliopancreatic diversion with duodenal switch is not necessary. Surg Obes Relat Dis 3:549-553.

46. Portenier DD, Grant JP, Blackwood HS, Pryor A, McMahon RL, et al. (2007) Expectant management of the asymptomatic gallbladder at Roux-en-Y gastric bypass. Surg Obes Relat Dis 3: 476-479.

47. Warschkow R, Tarantino I, Ukegjini K, Beutner U, Güller U, et al. (2013) Concomitant cholecystectomy during laparoscopic Roux-en-Y gastric bypass in obese patients is not justified: a meta-analysis. Obes Surg 23: 397-407.

48. Swartz DE, Felix EL (2005) Elective cholecystectomy after Roux-en-Y gastric bypass: why should asymptomatic gallstones be treated differently in morbidly obese patients? Surg Obes Relat Dis 1: 555-560

49. Baron TH, Vickers SM (1998) Surgical gastrostomy placement as access for diagnostic and therapeutic ERCP. Gastrointest Endosc 48: 640-641.

50. Choi EK, Chiorean MV, Coté GA, El Hajj II, Ballard D, et al. (2013) ERCP via gastrostomy vs. double balloon enteroscopy in patients with prio bariatric Roux-en-Y gastric bypass surgery. Surg Endosc 27: 2894-2899.

51. Dapri G, Himpens J, Buset M, Vasilikostas G, Ntounda R, et al. (2009) Video Laparoscopic transgastric access to the common bile duct after Roux-en-Y gastric bypass. Surg Endosc 23: 1646-1648.

52. Baron TH, Song LM, Ferreira LE, Smyrk TC (2012) Novel approach to therapeutic ERCP after long limb Roux en $Y$ gastric bypass surgery using transgastric self-expandable metal stents: experimental outcomes and first human case study. Gastrointest Endosc 7: 1258-1263.

53. Schreiner MA, Chang L, Gluck M, Irani S, Gan SI, et al. (2012) Laparoscopyassisted versus balloon enteroscopy-assisted ERCP in bariatric post-Rouxen-Y gastric bypass patients. Gastrointest Endosc. 75: 748-756.

54. Lee A, Shah JN (2013) Endoscopic approach to the bile duct in the patient with surgically altered anatomy. Gastrointest Endosc Clin N Am 23: 483504

55. Shah RJ, Smolkin M, Yen R, Ross A, Kozarek RA, et al. (2013) A multicenter, U.S. experience of single-balloon, double-balloon, and rotational overtube-assisted enteroscopy ERCP in patients with surgically altered pancreaticobiliary anatomy (with video). Gastrointest Endosc 77 : 593-600.

56. Koshitani T, Matsuda S, Takai K, Motoyoshi T, Nishikata M, et al. (2012) Direct cholangioscopy combined with double-balloon enteroscope-assisted endoscopic retrograde cholangiopancreatography. World J Gastroenterol 18: $3765-3769$

57. Milella M, Alfa-Wali M, Leuratti L, McCall J, Bonanomi G (2014) Percutaneous transhepatic cholangiography for choledocholithiasis after laparoscopic gastric bypass surgery. Int J Surg Case Rep. 5: 249-252.

58. Alfa-Wali M, Leuratti L, Mc Cal J (2013) A New Algorithm to Treat Common Bile Duct Stones After Gastric Bypass: The Role of PTC. Ob Surg 23: 10171243.

59. Flickinger EG, Sinar DR, Pories WJ, Sloss RR, Park HK, et al. (1985) The bypassed stomach. Am J Surg 149: 151-156.

60. Leuratti L, Di Simone MP, Cariani S (2013) Unexpected changes in the gastric remnant in asymptomatic patients after Roux-en-Y gastric bypass on vertical banded gastroplasty. Obes Surg 23: 131-139.
Int J Gastroenterol Disord Ther

ISSN: 2393-8498
IJGDT, an open access journal Volume 1. 2014. 101 